8-2018

\title{
Development of criteria highly suggestive of spinal tuberculosis
}

Gohar Javed

Aga Khan University, gohar.javed@aku.edu

Altaf Ali Laghari

Aga Khan University, altaf.alilaghari@aku.edu

Syed ljlal Ahmed

Aga Khan University

Sarosh Madhani

Aga Khan University

Ahmed Ali Shah

Aga Khan University, ahmed.alishah@aku.edu

See next page for additional authors

Follow this and additional works at: https://ecommons.aku.edu/pakistan_fhs_mc_surg_neurosurg

Part of the Neurology Commons, Neurosurgery Commons, and the Surgery Commons

\section{Recommended Citation}

Javed, G., Laghari, A., Ahmed, S., Madhani, S., Shah, A. A., Najmuddin, F., Khawaja, R. (2018). Development of criteria highly suggestive of spinal tuberculosis. World Neurosurgery, 116, e1002-e1006.

Available at: https://ecommons.aku.edu/pakistan_fhs_mc_surg_neurosurg/161 


\section{Authors}

Gohar Javed, Altaf Ali Laghari, Syed ljlal Ahmed, Sarosh Madhani, Ahmed Ali Shah, Faizuddin Najmuddin, and Reehana Khawaja

This article is available at eCommons@AKU: https://ecommons.aku.edu/pakistan_fhs_mc_surg_neurosurg/161 


\title{
Development of Criteria Highly Suggestive of Spinal Tuberculosis
}

\author{
Gohar Javed, Altaf Ali Laghari, Syed ljlal Ahmed, Sarosh Madhani, Ahmed Ali Shah, Faizuddin Najamuddin, \\ Reehana Khawaja
}

BACKGROUND: In a developing country there is a need for development of criteria that can be used for the diagnosis of spinal tuberculosis, which is common in that region.

METHODS: Demographic, clinical, and radiologic features of spinal tuberculosis and spinal epidural tumors have been compared statistically, and inferences have been drawn in terms of $\boldsymbol{P}$ values, sensitivity, specificity, positive predictive values, and negative predictive values.

RESULTS: A statistically significant relationship was found between spinal tuberculosis and spinal pain, fever, gradually progressive lower limb weakness, contrastenhancing epidural \pm paravertebral lesions, continuous levels affected, spinal deformity, and raised erythrocyte sedimentation rate.

CONCLUSIONS: These relationships were considered the most probable criteria for the diagnosis of spinal tuberculosis.

\section{INTRODUCTION}

I $\mathrm{n}$ tropical and developing countries, tuberculous infection is a major cause of morbidity and mortality. ${ }^{\mathrm{I}}$ Epidemiologically, spinal tuberculosis (STB) accounts for $15 \%$ of the total extrapulmonary cases of tuberculosis (TB) and approximately $2 \%$ of total cases of TB. ${ }^{2}$

Despite progress toward TB elimination, it is still an area of public health concern in the developing world. In the 2017 World
Health Organization Global Tuberculosis Report, the global incidence of TB was measured at $61 \%$, which accounts for 6.3 million new cases. The largest incidence of TB was reported in the countries of South and Southeast Asia. Furthermore, the study identified low-income countries as having a higher incidence of $\mathrm{TB}$, which in turn led to higher mortality due to this infection. The report also found that the majority of deaths due to TB could be prevented by timely diagnosis and early treatment. ${ }^{3}$ As mentioned earlier, spinal $\mathrm{TB}$ accounts for $15 \%$ of extrapulmonary tuberculosis, which makes it an area of considerable interest.

In moving toward reducing morbidity and mortality associated with this disease, timely diagnosis of spinal TB plays an important part. Delay in the diagnosis and treatment of STB can result in spinal cord compression and spinal deformity, which significantly affects the quality of life of patients. ${ }^{4}$ The incidence of spinal TB has increased even in developed parts of the world. An increase in cases of spinal TB from $14 \%$ to $45.2 \%$ among foreign-born residents in Barcelona, Spain over a period of ro years and a prevalence of 0.05 cases per 100,000 in the United States in $201 \mathrm{I}$ have been reported. ${ }^{5,6}$

Neoplasms are another group of diseases that commonly affect the spine. Primary tumors of spine are rare $^{7}$ and ro times less common than intracranial tumors. Therefore as most of the data suggest, these lesions are metastatic deposits that arise commonly from lung and breast cancers. ${ }^{8,9}$ The area most commonly affected within the spine by this disease is the vertebral bodies followed by paravertebral structures. ${ }^{\text {IO }}$

Clinically, STB has suggestive signs and symptoms. The study by Garg et $\mathrm{al}^{\mathrm{II}}$ identified a set of clinical and radiologic features, which they found to be specific for patients diagnosed with STB. These features included symptoms of back pain, spinal tenderness, and paraplegia, whereas radiologic features included destruction of intervertebral disk and vertebral bodies and presence of spinal deformity. ${ }^{\text {II }}$

\section{Key words \\ - Diagnostic criteria \\ - Erythrocyte sedimentation rate \\ - Spinal deformity \\ - Spinal TB}

\section{Abbreviations and Acronyms}

CRP: C-reactive protein

ESR: Erythrocyte sedimentation rate

MRI: Magnetic resonance imaging

STB: Spinal tuberculosis

TB: Tuberculosis
Department of Neurosurgery, Aga Khan University Hospital, Karachi, Pakistan

To whom correspondence should be addressed: Altaf Ali Laghari, M.B.B.S.

[E-mail: altaf.alilaghari@aku.edu]

Citation: World Neurosurg. (2018) 116:e1002-e1006.

https://doi.org/10.1016/j.wneu.2018.05.149

Journal homepage: www.WORLDNEUROSURGERY.org

Available online: www.sciencedirect.com

1878-8750/\$ - see front matter (c) 2018 Elsevier Inc. All rights reserved. 
The definitive diagnosis of STB, however, is based on laboratory and histopathologic investigation. Examples of pathologic tests are tuberculin tests, histopathology of any tissue obtained, and microbiologic culture of the mycobacterium. ${ }^{4,12,13}$

Radiologic examinations are a further necessary diagnostic step in evaluating spinal pathologies. Among these, magnetic resonance imaging (MRI) examination is the preferred modality. ${ }^{\text {I-I } 6}$ For spinal tumors, it can assist in identifying and differentiating between different types of tumors. Some articles, such as one by Arima et $a l,{ }^{17}$ suggest that MRI can do this task with an $89 \%$ accuracy. For spinal TB, MRI scans show distinct vertebral epidural involvement and inflammatory changes. ${ }^{\mathrm{I}}{ }^{8}$

With the incidence of spinal TB on the rise, it has become pertinent that a timely and quick diagnosis of this disease is made so that treatment of patients can be started and the significant burden of health expenses on patients living in the developing countries can be reduced. Keeping up with this intent, our paper aims to identify certain clinical, radiologic, and laboratory features for STB and compares it with those of spinal tumors.

\section{METHODOLOGY}

Our study is an audit-based review and analysis of cases that presented and were consequently treated as inpatients at Aga Khan University \& Hospital in Karachi, Pakistan from 20II to 2016. Patient medical record numbers were taken using the hospital's human information management systems. The sample size was calculated, and the sampling technique of our study was nonprobability.

Information regarding history and examination findings was then obtained from individual medical records of the patients, whereas radiologic and laboratory results were obtained from the hospital's clinical record system.

\section{Inclusion Criteria}

We included patients characterized by the following:

- Treated during the period mentioned

- Treated as inpatients

- Undergoing a procedure during which sample(s) for pathology was/were obtained

- With complete medical records

- With available gadolinium-enhanced MRI

- With laboratory data leading to a pathologic diagnosis of either TB or tumor

An ethical review committee exemption was obtained before the start of the study, following which the proforma to retrieve information was developed using the Epidata Manager Version 4.0 and data entry was done using Epidata Entry Client version 4.o.

The proforma included demographic patient information such as medical record number, age, and gender. Basic patient information such as body mass index, comorbids, and bacillus Calmette-Guerin vaccination status was also recorded.

As shown in Table 1, clinical signs and symptoms included the presence or absence of pain, neurologic deficits, fever, tenderness,
Table 1. Demographic and Radiological Features That Were

Recorded for Each Case

\begin{tabular}{l} 
1. Age \\
2. Gender \\
3. Comorbids \\
4. Onset \\
5. Pain \\
6. Fever \\
7. Neurologic deficit \\
a. Upper limb motor \\
b. Lower limb motor \\
c. Upper limb sensory \\
d. Lower limb sensory \\
8. Spinal deformity \\
9. TLC \\
10. ESR \\
11. CRP \\
12. Vertebral erosion \\
13. Posterior element erosion \\
14. Epidural lesion* \\
15. Paravertebral lesion* \\
16. Continuous levels \\
17. Noncontinuous levels \\
18. Deformity \\
TLC, total leukocyte count; ESR, erythrocyte sedimentation rate; CRP, C-reactive protein. \\
\hline
\end{tabular}

and spinal deformity. Mode of onset was described as acute for signs and symptoms manifesting in $\mathrm{II}_{4}$ days and chronic for $\geq$ I5 days. Pain scale was noted on a scale of $\mathrm{I}-$ Io. Fever was further explored as high grade, low grade, with chills, whereas neurologic deficits were further divided as motor and/or sensory and whether they were present in upper and/or lower limbs. Clinical investigations include total leukocyte count, erythrocyte sedimentation rate (ESR), and C-reactive protein (CRP) values at the time of disease.

Radiologic features included vertebral body and posterior element erosion and epidural and paravertebral components, which were further divided into contrast enhancing and noncontrast enhancing. The affected spinal region was also noted and divided into 7 categories, namely cervical, thoracic, lumbar, sacral, cervicothoracic, thoracolumbar, and lumbosacral. The diseased numbers of continuous and noncontinuous spinal levels were noted, and, finally, any spinal deformity such as kyphosis, scoliosis, and kyphoscoliosis were recorded.

\section{Exclusion Criteria}

Any patient with incomplete clinical, radiologic, and pathologic information (as defined in the inclusion criteria) was excluded. 
Table 2. Summary of Descriptive Frequencies and Statistical Analyses of Data

\begin{tabular}{|c|c|c|c|}
\hline & $\begin{array}{l}\text { Spinal Tumor } \\
\text { Number (\%) }\end{array}$ & $\begin{array}{c}\text { Spinal TB } \\
\text { Number (\%) }\end{array}$ & $P$ Value \\
\hline \multicolumn{4}{|l|}{ Gender } \\
\hline 1. Male & $31(62)$ & $20(40)$ & \\
\hline 2. Female & $19(38)$ & $30(60)$ & \\
\hline \multicolumn{4}{|l|}{ Onset } \\
\hline 1. Acute & $18(36)$ & $11(22)$ & \\
\hline 2. Chronic & $31(62)$ & $39(78)$ & \\
\hline Pain & $32(64)$ & $42(84)$ & 0.023 \\
\hline Fever & $2(4.0)$ & $10(20)$ & 0.014 \\
\hline Neurologic deficit & $32(64)$ & $27(54)$ & 0.309 \\
\hline 1. Upper limb motor & $5(10)$ & $5(10)$ & 1.000 \\
\hline 2. Lower limb motor & $36(72)$ & $34(68)$ & 0.663 \\
\hline 3. Upper limb sensory & $2(4.0)$ & 0 & 0.153 \\
\hline 4. Lower limb sensory & $13(26)$ & $9(18)$ & 0.334 \\
\hline Spinal region & & & 0.721 \\
\hline 1. Cervical & $3(6.0)$ & $2(4.8)$ & \\
\hline 2. Dorsal & $13(26)$ & $23(46)$ & \\
\hline 3. Lumbar & $11(22)$ & $12(24)$ & \\
\hline 4. Sacral & 0 & 0 & \\
\hline 5. Cervicodorsal & $1(2.0)$ & $1(2.0)$ & \\
\hline 6. Dorsolumbar & $3(6.0)$ & $4(8.0)$ & \\
\hline 7. Lumbosacral & $1(2.0)$ & 0 & \\
\hline Vertebral body erosion & $39(78)$ & $45(90)$ & 0.102 \\
\hline Posterior element erosion & $26(52)$ & $20(40)$ & 0.229 \\
\hline Epidural lesion & $33(66)$ & $44(91.7)$ & 0.002 \\
\hline Paravertebral lesion & $22(44)$ & $40(83.3)$ & 0.000 \\
\hline Continuous levels & & & 0.002 \\
\hline 1. Two & $14(28)$ & $32(64)$ & \\
\hline 2. Three & $5(10)$ & $6(12)$ & \\
\hline 3. Four & $2(4.0)$ & $1(2.0)$ & \\
\hline 4. Five & $4(8.0)$ & 0 & \\
\hline Noncontinuous levels & & & 0.018 \\
\hline 1. One & $20(40)$ & 7 (14) & \\
\hline 2. Two & 0 & $1(2.0)$ & \\
\hline 3. Three & $3(6.0)$ & 0 & \\
\hline 4. Four & $1(2.0)$ & $2(4.0)$ & \\
\hline 5. Five & $1(2.0)$ & $2(4.0)$ & \\
\hline 6. Six & 0 & 0 & \\
\hline & & & Continues \\
\hline
\end{tabular}

Table 2. Continued

\begin{tabular}{|c|c|c|c|}
\hline & $\begin{array}{c}\text { Spinal Tumor } \\
\text { Number (\%) }\end{array}$ & $\begin{array}{c}\text { Spinal TB } \\
\text { Number (\%) }\end{array}$ & $P$ Value \\
\hline Deformity & & & 0.503 \\
\hline 1. Kyphosis & $1(2.0)$ & $2(4.0)$ & \\
\hline 2. Scoliosis & 0 & 0 & \\
\hline 3. Kyphoscoliosis & 0 & $1(2.0)$ & \\
\hline ESR & 15.2 & 37.1 & 0.028 \\
\hline CRP & 11.5 & 12.5 & 0.896 \\
\hline \multicolumn{4}{|c|}{$\begin{array}{l}\text { For all results, } P \text { value was considered significant at }<0.05 \text { with a confidence interval } \\
\text { of } 95 \% \text {. } \\
\text { TB, tuberculosis; ESR, erythrocyte sedimentation rate; CRP, C-reactive protein. }\end{array}$} \\
\hline
\end{tabular}

The equal number of cases in both arms (i.e., 50 cases of STB and 50 cases of spinal tumors) made it easier to draw a comparison.

\section{STATISTICAL ANALYSES}

Statistical analyses were conducted using the IBM Statistical Package for the Social Sciences (IBM SPSS version 2I). Descriptive analysis of categorical data was shown in terms of frequencies and percentages, whereas that for continuous variables was presented as mean \pm standard deviation. The Pearson chi-squared test was used for comparing categorical variables wherever applicable. The confidence interval of our study was $95 \%$, and a P value $<0.05$ was considered significant. Positive and negative predictive value pertinent variables, along with their specificity and sensitivity, were also calculated.

\section{RESULTS}

The mean age of patients diagnosed with spinal TB was 46.20 (S.E \pm 2.8 ). More than half $(60 \%)$ of the patients were female with $78 \%$ presenting with chronic onset of symptoms. Within clinical signs and symptoms, pain was reported by $42(84 \%)$ cases, fever by Io $(20 \%)$, and neurologic deficit by $27(54 \%)$ cases. Within neurologic deficits, reported cases of motor weakness in upper limbs and lower limbs were 5 (10\%) and 34 (68\%), respectively. Sensory symptoms were only noted for lower limbs in $9(18 \%)$ of the cases. For all STB cases, the reported mean ESR was 37.17 (S.E \pm 5.4$)$ and CRP was 12.54 (S.E \pm 3.8). Statistics for radiologic features of cases showed 45 of them (90\%) had vertebral body erosion and 20 of them $(40 \%)$ had posterior element involvement. Cases that had contrast-enhancing epidural lesions were 44 (9r.7\%), and contrast-enhancing paravertebral lesions were $40(83.3 \%)$ after adjusting for missing values. Two continuous levels were affected in $32(64 \%)$, whereas I noncontinuous level was affected in 7 of the cases ( $14 \%)$.

For patients with spinal tumors, the mean age was 48.66 (S.E \pm 2.6). Thirty-one $(62 \%)$ of the patients were male. Within clinical signs and symptoms, pain was reported by $32(64 \%)$ cases, fever by $2(4 \%)$, and neurologic deficit by $32(64 \%)$ cases. Within 
neurologic deficits, reported cases of motor weakness in upper limbs and lower limbs were $5(10 \%)$ and $36(72 \%)$, respectively. Sensory symptoms in upper limbs and lower limbs were $2(4 \%)$ and I3 $_{3}(26 \%)$, respectively. For all spinal tumor cases, the reported mean ESR was I5.2I (S.E \pm 4.7$)$ and CRP was II.5I (S.E \pm 5.5$)$. Statistics for radiologic features reported for cases showed 39 $(78 \%)$ had vertebral body erosion and 26 (52\%) had posterior element involvement. Cases that had contrast-enhancing epidural lesions were $33(66 \%)$, and contrast-enhancing paravertebral lesions were $22(44 \%)$. Two continuous levels were affected in I4 $(28 \%)$, whereas I noncontinuous level was affected in $20(40 \%)$ of the cases.

Using the Pearson chi-squared test, categorical variables that were statistically associated with STB and spinal tumor were identified. Within clinical signs and symptoms, pain and fever were significantly associated $(\mathrm{P}<0.05)$ with STB, whereas for radiologic factors, contrast-enhancing epidural and paravertebral lesions and affected continuous levels were significantly associated $(\mathrm{P}<0.05)$ with STB. The only feature that was significantly associated $(\mathrm{P}<0.05)$ with spinal tumors was affected noncontinuous spinal levels. We also found statistically significant differences for ESR values between 2 groups $(\mathrm{P}<0.05)$. These findings are summarized in Table 2. We also measured the sensitivity, specificity, positive predictive value, and negative predictive value of significant variables in relation to spinal tuberculosis which are shown in Table 3.

\section{DISCUSSION}

In developing countries, tuberculous (TB) infections are still prevalent with a varied set of manifestations. Within the past few decades, a resurge of TB cases has been seen in the developing world. ${ }^{\mathrm{I} 9}$ Among TB infections, $2 \%$ affect the vertebral column. ${ }^{2} \mathrm{~A}$ study done in India showed that $30 \%$ of nontraumatic paresis was due to STB. ${ }^{13}$ Keeping in mind that the risk factor profile for TB in South Asian countries is similar to each other, the results of this study can be extrapolated to Pakistan to suggest that STB is highly prevalent in the country. Coupled with the emergence of multidrug-resistant strains and predominance in human immunodeficiency virus-infected patients, ${ }^{20}$ STB is a debilitating disease that, if left untreated, could severely impair the quality of life of patients.

The study done in India also found that spinal tumors comprised $10 \%$ of the cases that presented with nontraumatic paresis. As established, primary spinal tumors are rare $^{2 I}$ and most cases are found to be metastatic deposits of primary tumors of other parts of the body. A small number, $5 \%-$ I0\%, of these deposits are found in the epidural space and, if not treated, can cause significant neurologic damage ${ }^{22}$ including paralysis and loss of sphincter control. ${ }^{23}$ Therefore early diagnosis and prompt treatment can provide significant benefit in terms of the neurologic outcome for patients with spinal tumors. ${ }^{24}$

For spinal tuberculosis and spinal tumors, clinical judgment based on signs and symptoms of patients, correlated with specific radiologic imaging, could greatly improve the accuracy of diagnosis, eventually leading to a faster and better treatment process. ${ }^{20}$ However, for the purposes of our study, we focused on

Table 3. Sensitivity, Specificity, Positive Predictive Value (PPV), and Negative Predictive Value (NPV) of Significant Variables in Relation to Spinal Tuberculosis

Signs and Symptoms

\begin{tabular}{|c|c|c|c|c|}
\hline 1. Back pain & $56.7 \%$ & $69.2 \%$ & $84 \%$ & $36 \%$ \\
\hline 2. Fever & $83.3 \%$ & $43.9 \%$ & $54 \%$ & $36 \%$ \\
\hline 3. Spinal deformity & $50 \%$ & $50 \%$ & $5 \%$ & $95 \%$ \\
\hline $\begin{array}{l}\text { 4. Gradually progressive lower limb } \\
\text { weakness }\end{array}$ & $48.5 \%$ & $46.6 \%$ & $68 \%$ & $28 \%$ \\
\hline 5. Sensory deficit of lower limb & $40.9 \%$ & $47.4 \%$ & $16 \%$ & $74 \%$ \\
\hline 6. Sphincter control deficit & $47.5 \%$ & $46.1 \%$ & 84.7 & $12.2 \%$ \\
\hline
\end{tabular}

establishing criteria based on clinical and radiologic features of spinal TB.

In our study, we included 50 cases of STB and spinal tumors each, conducting an audit of major clinical and radiologic features that were seen in these patients. The mean age was found to be similar in both diseases, close to the end of the fourth decade of life. On an overall glimpse, most of the patients in both groups presented with overlapping clinical characteristics; however, the spinal tuberculous patients had a more insidious onset of symptoms.

The major clinical feature presenting in both diseases was pain. This symptom, however, was higher in percentage in patients with STB $(84 \%)$ as compared with those with spinal tumors $(54 \%)$. Twenty percent of the patients with STB reported fever as a symptom, whereas it was found among only $4 \%$ of cases of spinal tumors.

Clinical laboratory tests were limited to recording of total leukocyte count, ESR, and CRP measurements. On literature review, most studies did not mention these laboratory values as a part of their diagnostic process. In our study, laboratory values had a larger standard deviation and were not clinically significant. Therefore these variables were not considered as part of the final criteria.

The dorsal region of the spine was most affected in STB, with $51 \%$ of the lesions presenting in this area. This is similar to another study in which the results also showed a greater involvement of the thoracic spine in STB. ${ }^{4}$

Vertebral body erosion was commonly seen in I study by De Backer et al. ${ }^{\text {I9 }}$ Our study also showed similar findings as we encountered vertebral body erosion in $90 \%$ of our patients. STB lesions showed significant postcontrast enhancement in the epidural and paravertebral regions. This is similar to a study conducted in France, where $77 \%$ of cases had epidural involvement. ${ }^{\mathrm{I}}$

Under the guidance of our senior author (G.J.), 2 types of criteria have been developed to diagnose spinal tuberculosis.

Using the results of statistical analysis, we divided the features into 2 categories, namely most probable and possible for STB. The most probable features were those that had a statistically significant association with the disease and were verified by other statistical tests. Possible features were those that did not show a statistically significant association with a disease but, based on descriptive frequencies, could be linked to the disease. 
Most probable diagnostic criteria for STB:

- Pain

- Fever

- Gradually progressive lower limb weakness

- Contrast-enhancing epidural and paravertebral lesions

- Continuous (contiguous) levels affected

- Spinal deformity

- Raised ESR

Possible diagnostic criteria for STB:

- Female gender

- Presence of vertebral body erosion on radiologic findings
What makes this study noteworthy is the fact that it attempts to compare the overlapping features that can be found in both spinal tumors and spinal TB. Although numerous studies have been done to identify such features, they look at both pathologies individually rather than drawing a comparison between the 2. Our study aims to do the latter. This is helpful in drawing out criteria that can be used for diagnosis and detection of spinal tuberculosis. It holds particular importance in developing countries, where resources are limited and numerous investigations can increase the burden on the health system to make a final diagnosis. With a set of criteria in hand, clinicians would find it easier to approach such patients in a way that is not only cost effective but also accurate.

Our study, however, has few limitations as it is a retrospective study with a relatively smaller sample size. Therefore we intend to conduct a prospective study with a larger sample size to validate our results.

\section{REFERENCES}

I. Sternbach G. Percivall Pott: tuberculous spondylitis. J Emerg Med. I996;14:79-83.

2. Chen C-H, Chen Y-M, Lee C-W, Chang Y-J, Cheng C-Y, Hung J-K. Early diagnosis of spinal tuberculosis. J Formos Med Assoc. 20I6;II5:825-836.

3. Global tuberculosis report 20I7. Geneva: World Health Organization; 2017. Available at: http:// www.who.int/tb/publications/global_report/en/.

4. Turgut M. Spinal tuberculosis (Pott's disease): its clinical presentation, surgical management, and outcome. A survey study on 694 patients. Neurosurg Rev. 200I;24:8-I3.

5. Peghin M, Rodriguez-Pardo D, SanchezMontalva A, Pellisé F, Rivas A, Tortola T, et al. The changing epidemiology of spinal tuberculosis: the influence of international immigration in Catalonia, I993-2014. Epidemiol Infect. 2017;I45: 2I52-2I60.

6. De la Garza Ramos R, Goodwin CR, AbuBonsrah N, Bydon A, Witham TF, Wolinsky JP, et al. The epidemiology of spinal tuberculosis in the United States: an analysis of 2002-20II data. J Neurosurg Spine. 2017;26:507-512.

7. States CBTRotU. Statistical Report: Primary Brain Tumors in the United States, 1998-2002. Hinsdale (Illinois): Central Brain Tumor Registry of the United States; 2005.

8. Edelson RN, Deck MD, Posner JB. Intramedullary spinal cord metastases. Clinical and radiographic findings in nine cases. Neurology. I972;22: I222-I23I.
9. Jellinger K, Kothbauer P, Sunder-Plassmann E, Weiss R. Intramedullary spinal cord metastases. J Neurol. I979;220:3I-4I.

Io. Byrne TN. Spinal cord compression from epidural metastases. N Engl J Med. I992;327:6r4-6rg.

II. Garg RK, Somvanshi DS. Spinal tuberculosis: a review. J Spinal Cord Med. 2011;34:440-454.

I2. Gautam MP, Karki P, Rijal S, Singh R. Pott's spine and paraplegia. JNMA J Nepal Med Assoc. 2005;44: Io6-II5.

I3. Srivastava S, Sanghavi NG. Non traumatic paraparesis: aetiological, clinical and radiological profile. J Assoc Physicians India. 2000;48:988-99o.

I4. Desai S. Early diagnosis of spinal tuberculosis by MRI. Bone Joint J. I994;76:863-869.

15. Lindahl S, Nyman R, Brismar J, Hugosson C, Lundstedt C. Imaging of tuberculosis: IV. Spinal manifestations in 63 patients. Acta Radiol. 1996;37: 506-5II.

I6. Pertuiset E, Beaudreuil J, Lioté F, Horusitzky A, Kemiche F, Richette P, et al. Spinal tuberculosis in adults: a study of I03 cases in a developed country, I980-I994. Medicine (Baltimore). I999;78: 309-320.

I7. Arima H, Hasegawa T, Togawa D, Yamato Y, Kobayashi S, Yasuda T, et al. Feasibility of a novel diagnostic chart of intramedullary spinal cord tumors in magnetic resonance imaging. Spinal Cord. 20I4;52:769-773.

I8. Ousehal A, Gharbi A, Zamiati W, Saidi A, Kadiri R. [Imaging findings in I22 cases of Pott's disease]. Neurochirurgie. 2002;48:409-4I8.
I9. De Backer AI, Mortele KI, Vanschoubroeck II, Deeren D, Vanhoenacker FM, De Keulenaer BL, et al. Tuberculosis of the spine: CT and MR imaging features. Jbr Btr. 2005;88:92-97.

20. Shikhare SN, Singh DR, Shimpi TR, Peh WC Tuberculous osteomyelitis and spondylodiscitis Semin Musculoskelet Radiol. 20II;15:446-458.

2I. Mechtler LL, Nandigam K. Spinal cord tumors new views and future directions. Neurol Clin. 2013; 3I:24I-268.

22. Yanez ML, Miller JJ, Batchelor TT. Diagnosis and treatment of epidural metastases. Cancer. 2017;123: IIo6-III4.

23. Spinazze S, Caraceni A, Schrijvers D. Epidural spinal cord compression. Crit Rev Oncol Hematol. 2005;56:397-406.

24. Hammack JE. Spinal cord disease in patients with cancer. Continuum. 2012;18:312-327.

Conflict of interest statement: The authors declare that the article content was composed in the absence of any commercial or financial relationships that could be construed as a potential conflict of interest.

Received 11 March 2018; accepted 22 May 2018

Citation: World Neurosurg. (2018) 116:e1002-e1006.

https://doi.org/10.1016/j. wneu.2018.05.149

Journal homepage: www.WORLDNEUROSURGERY.org

Available online: www.sciencedirect.com

1878-8750/\$ - see front matter (C) 2018 Elsevier Inc. All rights reserved. 